\title{
AVALIAÇÃO DA QUALIDADE DO LEITE IN NATURA UTILIZADO EM LATICÍNIO DO SUL DO ESTADO DO ESPÍRITO SANTO
}

\section{QUALITY EVALUATION OF FRESH MILK USED IN DAIRY INDUSTRY IN SOUTHERN OF ESPÍRTO SANTO STATE}

\author{
${ }^{1}$ Renan de Mello Spadetto \\ ${ }^{2 *}$ Gabriel Domingos Carvalho \\ ${ }^{3}$ Clayton Perônico de Almeida \\ ${ }^{4}$ Dayse Aline Ferreira Silva Bartolomeu
}

\begin{abstract}
${ }^{1}$ Instituto Federal do Espírito Santo - Ifes Campus Piúma. E-mail: renanspadeto@hotmail.com ${ }^{2}$ Instituto Federal do Espírito Santo - Ifes Campus Piúma. E-mail: gabriel.carvalho@ifes.edu.br ${ }^{3}$ Instituto Federal do Espírito Santo - Ifes Campus Piúma. E-mail: cperonico@ifes.edu.br ${ }^{4}$ Instituto Federal do Espírito Santo - Ifes Campus Piúma. E-mail: dbartolomeu@ifes.edu.br *Autor de correspondência
\end{abstract}

Artigo submetido em 16/12/2020, aceito em 16/04/2021 e publicado em 10//05/2021.

Resumo: O leite é um produto importante na alimentação humana, sendo um alimento amplamente consumido e com alto nível e risco de contaminação, por isso, torna-se essencial a realização do controle de qualidade a fim de garantir os padrões mínimos de exigência do produto que chegam à mesa do consumidor. O leite de baixa qualidade apresenta capacidade industrial reduzida, ficando sujeito a alterações em suas características físico-químicas gerando descarte do produto e aumentando os custos de produção. Neste contexto, objetivou-se com este trabalho avaliar a qualidade do leite in natura utilizado no processo produtivo de laticínio do sul do estado do Espírito Santo. Os valores médios dos parâmetros composição físico-química, contagem de células somáticas (CCS), contagem bacteriana total (CBT), temperatura de recepção, acidez, $\mathrm{pH}$ e crioscopia, ficaram dentro dos padrões estabelecidos pela legislação vigente. No entanto, do total de 70 amostras analisadas, foram encontradas 37 (52,86\%) e 26 (37,14\%) com valores de CCS e CBT, respectivamente, acima dos padrões máximos determinados pela legislação. Dessa forma, se faz necessário a implementação de boas práticas de produção, adequações ao manejo sanitário do rebanho e higiene durante a ordenha, com adoção de programas de assistência técnica e capacitações para os produtores associados.

Palavras-chave: controle de qualidade, leite cru, segurança alimentar.

Abstract: Milk is an important product in human consumption, being a food widely consumed and with a high level and risk of contamination, therefore, it is essential to carry out quality control in order to guarantee the minimum standards of the product demand that reach the consumers. Low quality milk also has reduced industrial capacity, being subject to changes in its physical-chemical composition, generating product disposal and increasing production costs. In this context, the objective of this work was to evaluate the quality of fresh milk used in the production process of a dairy in southern of the state of Espírito Santo. The mean values of the physical-chemical composition, somatic cell count (CCS), total bacterial count (CBT), reception temperature, acidity, $\mathrm{pH}$ and cryoscopy, were within the standards established by the current legislation. However, of the total of 70 samples analyzed, 37 (52.86\%) and 26 (37.14\%) were found with CCS and CBT values, respectively, above the maximum standards determined by legislation. Thus, it is necessary to 
implement good production practices, adaptations to herd health management and hygiene during milking, with the adoption of technical assistance programs and training for associated producers.

Keywords: food safety, quality control, raw milk.

\section{INTRODUÇÃO}

A atividade leiteira no Brasil, realizada em cerca de 1,35 milhões de propriedades, contribui diretamente com 5 milhões de empregos, sendo considerada o segundo setor que mais emprega no país, perdendo apenas para a construção civil. Além disso, o setor leiteiro gera, aproximadamente 100 bilhões por ano de lucro, valor este que representa $76 \%$ dos produtos gerados pela pecuária nacional (GUIMARÃES, 2017).

Segundo dados da FAO - Food and Agriculture Organization of the Unites Nations, em 2017, o Brasil ocupou a quinta posição mundial no ranking de produção de litros de leite, ficando atrás da Índia, Estados Unidos, China e Paquistão, respectivamente (FAO, 2018).

O leite é definido como o produto oriundo da ordenha completa e ininterrupta, em condições de higiene, de vacas sadias, bem alimentadas e descansadas (BRASIL, 2002). O leite, quanto ao seu aspecto e cor, é um líquido branco, opaco, duas vezes mais viscoso que água, com sabor e odor característicos, e quando produzido de forma adequada, fica isento de substâncias estranhas e colostro (VALSECHI, 2001; BRASIL 2018a).

O leite é uma excelente fonte nutritiva, apresentando em sua composição alto teor de cálcio, proteínas, ácidos graxos, carboidratos, vitaminas, sais minerais e água, sendo um dos produtos mais completos nutricionalmente, apresentando-se na dieta humana em todas as faixas etárias (SILVA et al., 2014).

Por outro lado, o leite de baixa qualidade tem capacidade industrial reduzida, ficando sujeitos a alterações em sua composição físico-químicas gerando descarte do produto e aumentando os custos de produção.

Por ser um produto extremamente importante na alimentação humana e de natureza perecível é essencial a realização do controle de qualidade do leite, a fim de garantir os padrões mínimos de exigência do produto que chega ao consumidor.

Neste contexto, objetivou-se com este trabalho realizar um estudo para avaliar se os parâmetros físico-químicos e de qualidade do leite cru refrigerado (leite in natura) utilizado no processo produtivo de um laticínio do sul do estado do Espírito Santo atende à legislação vigente, estando dentro dos padrões de qualidade exigidos pelo Ministério da Agricultura, Pecuária e Abastecimento - MAPA (BRASIL, 2002; BRASIL, 2018a; BRASIL, 2018b).

\section{REFERENCIAL TEÓRICO}

O leite é uma secreção das glândulas mamárias de fêmeas mamíferas que é utilizado para nutrir e proteger imunologicamente os filhotes, sendo essencial nos primeiros meses de vida (CHAVES, 2011).

O leite usado como alimento pelo ser humano é obtido de diversas espécies animais e geralmente designado segundo a espécie ordenhada (GUIMARÃES, 2017). Tonini (2014) cita que além do leite de vacas, o leite de animais como búfalas, cabras e ovelhas, também podem ser usados para o consumo humano.

Por definição físico-química, o leite é uma suspensão coloidal de micelas de caseínas ligadas ao cálcio e fosforo; emulsão de vitaminas lipossolúveis e glóbulos de gordura; solução de lactose; sais minerais e vitaminas hidrossolúveis e proteínas solúveis em água (SANTOS e FONSECA, 2007). 
Tonini (2014) relata a importância de conhecer a composição, uma vez que esta reflete a qualidade, define propriedades sensoriais e tecnológicas de seus derivados, como iogurtes, queijos, manteigas e outros produtos lácteos. Os teores da composição físico-química do leite podem variar em função dos meses do ano, devido a possíveis relações com a qualidade do alimento consumido pelos animais e ao manejo nutricional adotado por cada produtor (BORGES et al., 2009). Por outro lado, a qualidade do leite tem relação com o número inicial de bactérias no úbere do animal e ao ambiente externo no ato da ordenha (PEDRICO et al., 2009). Para Pereira et al. (2012), a má qualidade do leite se deve a fatores relacionados a deficiências no manejo e na ordenha; altos índices de mastite; erros na manutenção e desinfecção dos equipamentos, mão de obra desqualificada e refrigeração inexistente ou ineficiente, além de fatores como a manipulação e tempo no transporte.

A partir da década de 1950, foi aprovado o Regulamento de Inspeção Industrial de Produtos de Origem Animal (RIISPOA), a fim de fiscalizar a pasteurização e tornar obrigatória a inspeção, pelo Serviço de Inspeção Federal para o comércio interestadual e internacional (BACCHI, 2019). Com intuito de padronizar, aperfeiçoar e regulamentar as boas práticas ligadas à cadeia láctea, além de diminuir as perdas econômicas geradas pela elevada acidez no leite e altos níveis de mastite, o Ministério da Agricultura divulgou, em 1997, a primeira proposta do Plano Nacional de Melhoria da Qualidade do Leite (PNMQL), que objetivava reduzir as perdas quantitativas de matéria prima, aumentar vida de prateleira e o padrão dos derivados do leite (FELIPUS, 2017).

Em setembro de 2002, no Brasil, foi publicada a Instrução Normativa $n^{0} 51$ do MAPA, na qual foram aprovados os regulamentos técnicos para a produção, identidade, qualidade, refrigeração e transporte do leite (BRASIL, 2002). No entanto, conforme Nero et al. (2005), os padrões estabelecidos nesta Instrução Normativa não foram alcançados. Nesse sentido, no ano de 2011, o MAPA publicou a Instrução Normativa $n^{\circ}$ 62, com intuito de atualizar e aperfeiçoar as cobranças da IN $n^{0}$ 51/2002 com padrões de qualidade mais rígidos (BRASIL, 2011).

Com o objetivo novamente não alcançado, o MAPA publicou em novembro de 2018 as Instruções Normativas (IN $\mathrm{n}^{0} 76$ e $\mathrm{n}^{0}$ 77), que entraram em vigor em maio de 2019, fixando os regulamentos técnicos da identidade e as características de qualidade que devem apresentar o leite cru refrigerado, o leite pasteurizado e o leite pasteurizado tipo A (BRASIL, 2018a), além dos critérios e procedimentos para a produção, acondicionamento, conservação, transporte, seleção e recepção do leite cru (BRASIL, 2018b).

\section{MATERIAIS E MÉTODOS}

Este estudo foi realizado no período de março a junho de 2020, em uma associação instalada na região sul do estado do Espírito Santo, que recebe leite proveniente de 27 tanques de resfriamento, de uso individual e comunitário, localizados em 05 municípios, totalizando 35 produtores. A associação está em atividade há 26 anos e processa um volume diário médio de 5000 litros de leites, destinados à venda de leite integral (leite de saquinho) e a produção de queijos, ricota e iogurtes.

O leite recebido pelo laticínio é coletado em tanques de resfriamento, produzido por rebanhos bovinos leiteiros compostos de animais mestiços holandêszebu, distintos em composições genética e, cuja alimentação é realizada em pastagens, na maior parte do ano.

Os dados obtidos foram referentes as amostras coletas por técnicos capacitados no ato do recebimento do leite 
na plataforma do laticínio para as análises de crioscopia, teste de antibiótico, teste de Dornic; temperatura de recebimento e $\mathrm{pH}$, sendo coletadas em amostras diretamente do caminhão de transporte (BRASIL, 2018a; BRASIL, 2018b). Já as amostras para avaliação da composição físicoquímica do leite (gordura, proteína, lactose, estrato seco desengordurado (ESD) e estrato seco total (EST), Contagem de Células Somáticas (CCS) e Contagem Bacteriana Total (CBT) foram realizadas em coletas diretamente nos tanques de resfriamento dentro das propriedades analisadas (BRASIL, 2018a; BRASIL, 2018b). As amostras para análise de CCS foram coletadas em frasco de $100 \mathrm{~mL}$ contendo conservante Bronopol (2-bromo2nitropropano-1,3-diol). Em outro frasco, contendo o conservante azidiol, foram coletadas amostras de leite para análise de CBT, sendo os frascos mantidos em caixas isotérmicas e encaminhados ao Laboratório da Empresa Brasileira de Pesquisa Agropecuária - EMBRAPA Gado de Leite, em Coronel Pacheco - MG.

As amostras para composição físico-química, CCS e CBT foram coletadas uma vez ao mês entre o período de março a maio, enquanto as amostras para as análises de crioscopia, teste de antibiótico, teste de Dornic, temperatura de recebimento e $\mathrm{pH}$ foram coletadas entre os dias 26 de maio a 16 de junho de 2020 .

Para a determinação de acidez em Graus Dornic, seguiu-se a metodologia do Instituto Adolfo Lutz (1985, p. 203 - 204), utilizando-se $10 \mathrm{~mL}$ de leite com seringa de plástico higienizada e colocadas em tubos com superfície branca, sendo adicionada à amostra do leite 5 gotas de solução de fenolftaleína e agitada levemente. Após isso, foi pressionada a torneira do acedímetro, para gotejar a solução Dornic, agitando, lentamente, cada 0,1 mL da solução de hidróxido de sódio $\mathrm{N} / 9$ equivale a $1^{\circ} \mathrm{D}$.

O teste de antibiótico foi realizado em kits BetaStar ${ }^{\circledR}$ S4D para a detecção rápida de antibióticos beta-lactâmicos, tetraciclinas, estreptomicina e cloranfenicol em leite cru, utilizando-se leitores Neogen ${ }^{\circledR}$.

A crioscopia foi realizada em equipamento crioscópico Laktron $^{\circledR}$. O método utilizado para a determinação de $\mathrm{pH}$ na amostra de leite seguiu a técnica preconizada pelo Instituto Adolfo Lutz (1985, p. 27), na qual calibrou-se o pHmetro com soluções tampão pH 4,0 e 7,0 e, adicionou-se $50 \mathrm{~mL}$ da amostra de leite previamente homogeneizado em um bécker de $100 \mathrm{~mL}$, sendo inserido o eletrodo do aparelho na amostra e esperouse estabilizar o resultado do valor de $\mathrm{pH}$.

Os dados obtidos, a partir dos resultados das análises laboratoriais realizadas pelo laticínio, foram tabulados e procedeu-se as análises estatísticas (média, mínimo, máximo e desvio padrão), permitindo uma avaliação de comportamento dos mesmos, para cada análise realizada, e a comparação os padrões da Instrução Normativa $\mathrm{N}^{\circ}$ 76/2018.

\section{RESULTADOS E DISCUSSÃO}

Os valores médios da gordura, proteína, lactose, estrato seco desengordurado (ESD) e estrato seco total (EST), Contagem de Células Somáticas (CCS) e Contagem Bacteriana Total (CBT) estão demonstrados na Tabela 1. Os resultados médios observados para os parâmetros da composição do leite processado no laticínio apresentam-se dentro dos padrões estabelecidos pela legislação vigente, onde é citado que o leite deve atender aos requisitos físicoquímicos de gordura (mínimo de $3 \mathrm{~g} / 100$ g), acidez titulável $(0,14$ a 0,18 g de ácido láctico/100 mL), lactose anidra (mínimo 4,3 g/ 100 g), extrato seco desengordurado (mínimo de 8,4 g /100 g), índice crioscópico $\left(-0,530^{\circ} \mathrm{H}\right.$ a $\left.-0,550^{\circ} \mathrm{H}\right)$, proteína (mínimo de 2,9 g /100 g) e sólidos totais (mínimo 11,4 g/ 100 g) (BRASIL, 
2018a). No entanto, as médias de CBT e CCS, das amostras do leite cru refrigerado de tanques individuais ou de uso comunitário, ficaram acima do permitido em legislação, podendo observar-se nessas amostras desvios padrão elevados entre as amostras avaliados, ou seja, algumas amostras com contagens baixas e outras extremamente altas.

Nas amostras coletadas no laticínio, diretamente do caminhão no momento de recepção, não foram encontrados problemas com resíduos de antibióticos e adulteração no leite por presença de água. Os valores médios, mínimo e máximo para temperatura de recepção, acidez, $\mathrm{pH}$ e crioscopia estão demostrados na Tabela 2.

Tabela 1: Valores médios e desvio padrão dos parâmetros composição do leite, contagem de células somáticas e contagem bacteriana total.

\begin{tabular}{|c|c|}
\hline Análises $(n=70)$ & Média/desvio padrão \\
\hline GOR (\%) & $3,9 \pm 0,5$ \\
\hline PRO (\%) & $3,3 \pm 0,2$ \\
\hline LAC (\%) & $4,4 \pm 0,1$ \\
\hline EDT (\%) & $12,40 \pm 0,6$ \\
\hline EST (\%) & $8,6 \pm 0,2$ \\
\hline CCS (CS/mL) & $639,6 \pm 534,0$ \\
\hline CBT (UFC/mL) & $306,4 \pm 282,9$ \\
\hline \multicolumn{2}{|c|}{$\begin{array}{l}\text { *GOR - gordura; PRO - proteína; LAC - lactose; } \\
\text { EST - estrato seco total; ESD - estrato seco } \\
\text { desengordurado; CCS - contagem de células } \\
\text { somáticas; CBT - contagem bacteriana total. Fonte } \\
\text { Os autores (2020). }\end{array}$} \\
\hline
\end{tabular}

Tabela 2: Valores médios, mínimo e máximo para temperatura de recepção, acidez, $\mathrm{pH}$ e crioscopia das amostras coletadas do caminhão no laticínio.

\begin{tabular}{lccc}
\hline Análises & Média & Mínimo & Máximo \\
\hline Temperatura $\left({ }^{\circ} \mathrm{C}\right)$ & 6,55 & 6,0 & 7,0 \\
Acidez $\left({ }^{\circ} \mathrm{D}\right)$ & 0,17 & 0,16 & 0,18 \\
$\mathrm{pH}$ & 6,68 & 6,50 & 6,80 \\
Índice & $-0,54$ & $-0,53$ & $-0,55$ \\
Crioscópico $\left({ }^{\circ} \mathrm{H}\right)$ & & & \\
\hline
\end{tabular}

Fonte: Os autores (2020).
As análises de $\mathrm{pH}$ apresentaram valores dentro da faixa considerado normal. A avaliação da acidez e do pH são parâmetros importantes a serem avaliados uma vez que podem ser um indicador da qualidade sanitária e estabilidade térmica do leite (ROCHA et al., 2016). Todas as amostras avaliadas apresentaram uma acidez variando dentro da faixa de exigência proposta pela legislação vigente, conferindo a normalidade de um dos parâmetros mais importantes para 0 beneficiamento dessa matéria-prima, uma vez que, quando os valores estão acima do limite máximo estabelecido pela legislação, o leite torna-se impróprio para o consumo, pois essa elevação indica atividade microbiana (ALVES et. al., 2020). Qualquer aumento de acidez, além dos valores normais, é um indicativo da ação de microrganismos sobre a lactose, que é metabolizada à ácido láctico (MAGRI, 2015).

Segundo a legislação, os valores do ponto de congelamento máximo do leite aceitos são a variação de $-0,530{ }^{\circ} \mathrm{H}$ à $0,555{ }^{\circ} \mathrm{H}$, sendo ${ }^{\circ} \mathrm{H}$ a escala Hortvet, cuja variação equivale de $-0,512^{\circ} \mathrm{C}$ a $-0,531^{\circ} \mathrm{C}$. Neste estudo, o ponto de congelamento das amostras de leite avaliadas apresentou uma variação de $-0,530$ a $-0,550{ }^{\circ} \mathrm{H}$, sendo verificada a conformidade com a legislação. A determinação de fraude do leite por adição de água é a aplicação mais usual da crioscopia para os laticínios, em razão da diminuição do valor nutricional, aumento dos custos de transporte e da energia empregada no processamento, além da queda do rendimento na fabricação de derivados e contribuição para contaminação microbiana (MENDONÇA et. al., 2009).

A temperatura de recepção das amostras também atendeu à $\mathrm{IN} \mathrm{n}^{\circ}$ 76/2018, onde o leite recebido no estabelecimento estava abaixo de $7{ }^{\circ} \mathrm{C}$. Este procedimento permite que a carga microbiana estabilize, pois o leite é uma fonte completa de nutrientes para uma grande quantidade de organismos e muitas espécies de bactérias 
multiplicam-se rapidamente nessa matériaprima, principalmente se as temperaturas forem apropriadas à sua multiplicação (MIGUEL et al., 2010). Quando as temperaturas estão favoráveis para a proliferação das bactérias, o leite coagula e adquiri sabor e odores desagradáveis (ZOCCHE, 2002).

Do total de 70 amostras analisadas, foram encontrados 37 (52,86\%) resultados de CCS e 26 (37,14\%) resultados de CBT acima dos padrões máximos determinados pela IN 76 (Figura 1), não estando em conformidade com a legislação.

Figura 1: Porcentagem de produtores que estão em conformidade com a legislação vigente para as análises de CCS e CBT.

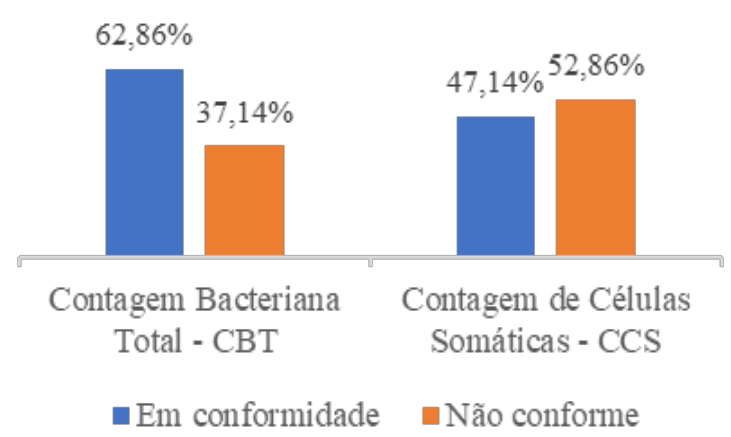

Fonte: Os autores (2020).

As médias para as amostras que estavam em conformidade com a legislação foram de $246.240 \mathrm{CS} / \mathrm{mL}$ e 125 . $630 \mathrm{UFC} / \mathrm{mL}$, já para o grupo fora das conformidades essa média foi de 990.480 $\mathrm{CS} / \mathrm{mL}$ e $612.230 \mathrm{UFC} / \mathrm{mL}$ (Tabela 3).

A IN $n^{\circ} 76$, de 26 de novembro de 2018, estabelece que o leite cru refrigerado de tanque individual ou de uso comunitário deve apresentar médias geométricas trimestrais de Contagem Padrão em Placas de no máximo 300.000 UFC/mL (trezentas mil unidades formadoras de colônia por mililitro) e de Contagem de Células Somáticas de no máximo $500.000 \mathrm{CS} / \mathrm{mL}$ (quinhentas mil células por mililitro) (BRASIL, 2018a).
Tabela 3: Valores médios e desvio padrão dos parâmetros para contagem de células somáticas (CCS) e contagem bacteriana total (CBT) quanto à conformidade com a legislação (IN nº 76/2018).

\begin{tabular}{lcc}
\hline $\begin{array}{l}\text { Conformidade } \\
\text { com a legislação }\end{array}$ & $\begin{array}{c}\text { CCS } \\
\left(\times 10^{3} C S / m L\right)\end{array}$ & $\begin{array}{c}\text { CBT } \\
\left(\times 10^{3} U F C / m L\right)\end{array}$ \\
\hline Em & 246,24 & 125,63 \\
conformidade & $\pm 140,64$ & $\pm 84,13$ \\
Não conforme & 990,48 & 612,23 \\
& $\pm 510,53$ & $\pm 232,24$
\end{tabular}

Fonte: Os autores (2020).

A CCS é indicativa da sanidade da glândula mamária (SANTOS e FONSECA, 2007. A CCS na glândula mamária sadia varia de 20.000 a $50.000 \mathrm{CS} / \mathrm{mL}$, considerando o valor limite de até 100.000 células/mL para ausência de infecção intramamária (DIAS e ANTES, 2014). O aumento dessa contagem repercute em consequências tecnológicas para a produção, gerando diminuição no rendimento de fabricação de queijos e inibição da ação de fermentos lácteos em queijos e iogurtes (MELO et al., 2013).

Um leite com baixos níveis de CCS permitirá maior rendimento e tempo de prateleira, resultando em maior segurança alimentar, atendendo as legislações e gerando maior lucratividade para indústrias e produtores (ALMEIDA, 2013).

Como forma de classificação e identificação das amostras de leite quanto aos valores de CCS e CBT, foram divididas em faixas de acordo com os resultados analisados, conforme observamos nas tabelas 4 e 5 .

Em relação aos valores de CCS notou-se que das $47,14 \%$ das amostras em conformidade, 30\% estavam entre 0 e $250.000 \mathrm{CS} / \mathrm{mL}$ e $17,14 \%$ apresentavam valores entre 251.000 e $500.000 \mathrm{CS} / \mathrm{mL}$. Dentre os 52,86\% das amostras em não conformidade, observou-se resultados em três faixas, de 501.000 a $700.000 \mathrm{CS} / \mathrm{mL}$, de 701.000 a $1.000 .000 \mathrm{CS} / \mathrm{mL}$ e acima de 1.000.000 CS/mL, valores correspondentes 
à 18,57\%, 20\% e 14,29\% das amostras, respectivamente (Tabela 4).

Tabela 4: Estratificação das amostras analisadas com relação à contagem de células somáticas (CCS).

\begin{tabular}{llcc}
\hline $\begin{array}{l}\text { Conformidade } \\
\text { com a legislação }\end{array}$ & $\begin{array}{l}\text { CCS } \\
\text { x10 }\end{array}$ CS/mL & $\begin{array}{c}\text { \% das } \\
\text { amostras }\end{array}$ & $\begin{array}{c}\mathbf{N}^{\mathbf{0}} \text { de } \\
\text { amostras }\end{array}$ \\
\hline Em a 250 & $30,00 \%$ & 21 \\
conformidade & 251 a 500 & $17,14 \%$ & 12 \\
\hline & 501 a 700 & $18,57 \%$ & 13 \\
Não conforme & 701 a 1.000 & $20,00 \%$ & 14 \\
& $>1.000$ & $14,29 \%$ & 10
\end{tabular}

Fonte: Os autores (2020).

Para as amostras de CBT que se encontravam em conformidade (62,86\%), dessas, 38,57\% apresentavam valores entre 0 e $150.000 \mathrm{UFC} / \mathrm{mL}$ e, 24,29\% entre 151.000 e 300.000 UFC/mL. Das 37,14\% amostras não conformes, $15,72 \%$ estavam entre 301.000 a $500.000 \mathrm{UFC} / \mathrm{mL}, 10 \%$ entre 501.000 e $700.000 \mathrm{UFC} / \mathrm{mL}, 11,43 \%$ entre 701.000 e $1.000 .000 \mathrm{UFC} / \mathrm{mL}$ e, $2,85 \%$ apresentaram valores acima de 1.000.000 UFC/mL (Tabela 5).

Tabela 5: Estratificação das amostras analisadas com relação à contagem bacteriana total (CBT).

\begin{tabular}{llcc}
\hline $\begin{array}{l}\text { Conformidade } \\
\text { com a legislação }\end{array}$ & $\begin{array}{l}\text { CBT } \\
\text { x10 }\end{array}$ & $\begin{array}{c}\text { \% das } \\
\text { am }\end{array}$ & $\begin{array}{c}\mathbf{N}^{\mathbf{0}} \text { de } \\
\text { amostras }\end{array}$ \\
\hline Conformidade & a 150 & $38,57 \%$ & 27 \\
& 151 a 300 & $24,29 \%$ & 17 \\
\hline \multirow{2}{*}{ Não conforme } & 301 a 500 & $12,86 \%$ & 9 \\
& 701 a 700 & $10,00 \%$ & 7 \\
& $>1.000$ & $2,85 \%$ & 2
\end{tabular}

Fonte: Os autores (2020).

A contagem bacteriana total é um teste utilizado para avaliar a qualidade microbiológica do leite (HILL et al., 2011). O aumento da CBT pode ser causado por contaminação do úbere, rotina de ordenha inadequada, equipamentos contaminados, refrigeração e transporte inadequados do leite (NEVES et al., 2019). $\mathrm{O}$ tempo de armazenagem prolongado favorece o crescimento de microrganismos psicrotróficos que podem ocasionar o aumento de CBT (HAYES et al., 2001). Além do efeito de estocagem e transporte, a contagem inicial do leite também pode determinar o grau de multiplicação bacteriana (PANTOJA et al., 2009).

Taffarel et al. (2013) citam que a CBT está relacionada com a composição do leite e com as alterações nos produtos fabricados pela indústria. Em leites com altos níveis de CBT, a fermentação da lactose por bactérias produz ácido lático causando a acidez, a qual é um problema para os laticínios. A produção de enzimas extracelulares, como lipases e proteases de origem microbiana, altera o sabor e o odor, causando à perda de consistência na formação do coágulo para fabricação do queijo e a gelatinização do leite longa-vida, diminuindo o tempo de prateleira dos produtos.

A diminuição da CBT é o primeiro parâmetro de qualidade a ser alcançado pelo produtor, uma vez que esse apresenta maior facilidade de implantação de mudanças de manejo e baixo custo para realização das medidas corretivas (PAIVA et al., 2012).

\section{CONCLUSÕES}

Os parâmetros de composição do leite, temperatura de recepção, acidez, $\mathrm{pH}$ e crioscopia avaliados estão dentro dos padrões exigidos pela legislação brasileira. No entanto $52,86 \%$ das amostras para CCS e $37,14 \%$ para CBT estão em não conformidade com o preconizado na IN $n^{0} 76 / 2018$. Dessa forma se faz necessário a devida aplicação das boas práticas de produção, adequações ao manejo sanitário do rebanho e de higiene durante a ordenha, com adoção de programas de assistência técnica e capacitações para os produtores associados, no intuito de gerar um alimento seguro à mesa do consumidor, adquirindo 
futuramente um valor agregado satisfatório pelo leite produzido.

\section{AGRADECIMENTOS}

À Associação participante deste estudo e ao curso de Pós-graduação em Controle de Qualidade e Segurança de Alimentos do Instituto Federal do Espírito Santo - Ifes Campus Piúma.

\section{REFERÊNCIAS}

ALMEIDA, Thamara Venâncio. Parâmetros de qualidade do leite cru bovino: Contagem Bacteriana Total e Contagem de Células Somáticas. Seminário apresentado ao Curso de Mestrado em Ciência Animal da Escola de Veterinária e zootecnia da Universidade Federal de Goiás. 2013.

ALVES, Marilia Patrício et al. Rev.Bras.de Gestão Ambiental (Pombal, PB)14(01)1727, jan./mar. 2020.

BACCHI, Matheus Demambre. Análise espacial da produção de leite no Brasil. Dissertação de Mestrado (Universidade de São Paulo - Escola Superior de Agricultura “Luiz de Queiroz”). 2019.

BORGES, Karen Apellanis et al. Avaliação da qualidade do leite de propriedades da região do Vale do Taquari no estado do Rio Grande do Sul. Acta Scientiae veterinariae. v.37 n.1. p. 39-44, 2009.

BRASIL. Instrução Normativa $n^{\circ}$ 42, de 20 de dezembro de 1999. Altera o Plano Nacional do Controle de Resíduos em Produtos de Origem Animal - PNCR e os Programas de Controle de Resíduos em Carne - PCRC, Mel - PCRM, Leite - PCRL e Pescado - PCRP. Diário Oficial da República Federativa do Brasil. Brasília, DF, 22 dez. 1999. Seção 1, no 244, p.253267.
BRASIL. Instrução Normativa $n^{0} 51$ de 18 de setembro de 2002. Regulamento Técnico de Produção, Identidade e Qualidade de Leite Tipo A, Tipo B, Tipo C e Cru refrigerado. Diário Oficial da República Federativa do Brasil, Brasília, 29 set. 2002. Seção 1, p.13.

BRASIL. Instrução Normativa $n^{0} 62$ de 29 de dezembro de 2011. Altera a Instrução Normativa MAPA $\mathrm{n}^{\circ}$ 51, de 18 de setembro de 2002. Diário Oficial da República Federativa do Brasil, Brasília, 30 dez. 2011. Seção 1, p.6.

BRASIL. Instrução Normativa $n^{0} 76$ de 26 de novembro de 2018. Regulamenta a identidade e as características de qualidade que devem apresentar o leite cru refrigerado, o leite pasteurizado e o leite pasteurizado tipo A. Diário Oficial da República Federativa do Brasil, Brasília, 26 nov. Seção 1, p 9. 2018a.

BRASIL. Instrução Normativa $\mathrm{n}^{\circ} 77$ de 26 de novembro de 2018. Define os critérios e procedimentos para a produção, acondicionamento, conservação, transporte, seleção e recepção do leite cru em estabelecimentos registrados no serviço de inspeção oficial. Diário Oficial da República Federativa do Brasil, Brasília, 26 nov. Seção 1, p 9. 2018b.

CHAVES, Ana Carolina Sampaio Doria. Leites. In: KOBLITZ, M. G. B. Matériasprimas alimentícias: composição e controle de qualidade. Rio de Janeiro: Guanabara Koogan, 2011. p. 147-185.

DIAS, Juliana Alves; ANTES, Fabiane Goldschimidt. Qualidade físico-química, higiênico-sanitária e composicional do leite cru: indicadores e aplicações práticas da Instrução Normativa. Porto Velho, RO: Embrapa Rondônia, 2014.

FAO. Food and Agriculture Organization. Dairy Market Review, 2018. Disponível 
em:http://www.fao.org/3/I9210EN/i9210en .pdf. Acessado em: 03 de março de 2020.

FELIPUS, Nadine Cristina. Impacto do transporte a granel na qualidade microbiológica e físico-química e na composição do leite cru refrigerado em indústria de laticínios. Dissertação (Metrado em Ciência Animal) Universidade do Estado de Santa Catarina - Lages, 2017.

GUIMARÃES, Anicézio José Silveira. Avaliação da qualidade do leite cru refrigerado em relação ao enquadramento legal e o efeito da sazonalidade sobre o preço pago aos produtores. Dissertação (Mestrado em Gestão Organizacional) Universidade Federal de Goiás - Catalão, 2017.

HAYES MC; RALYEA RD; MURPHY SC; CAREY NR; SCARLETT JM; BOOR KJ. Identification and characterization of elevated microbial counts in bulk tank raw milk. J. Dairy Sci., v.84, n.1, p.292- 298, 2001.

HILL, João Ari Gualberto et al. Qualidade do leite na região sudoeste do Paraná. Londrina: IAPAR, 2011. 56 p. (IAPAR, Boletim técnico, 76).

INSTITUTO ADOLFO LUTZ. Normas Analíticas do Instituto Adolfo Lutz. v. 1: Métodos químicos e físicos para análise de alimentos, 3. ed. São Paulo: IMESP, 1985, p. 203-204.

INSTITUTO ADOLFO LUTZ. Normas Analíticas do Instituto Adolfo Lutz. v. 1, Métodos químicos e físicos para análise de alimentos, 3. ed. São Paulo: IMESP, 1985. p. 27.

MAGRI, Luiz Paulo. Quantificação de acidez titulável e $\mathrm{pH}$ utilizando técnica potenciométrica como indicador de qualidade do leite bovino. Dissertação (Mestrado em Ciência e Tecnologia em
Leite e Derivados) Universidade Federal de Juiz de Fora, Juiz de Fora, 2015.

MELO, Aurélio Ferreira et al. Qualidade do leite cru tipo c e refrigerado em sistemas leiteiros tradicionais do sudoeste goiano. Rev. Inst. Laticínios Cândido Tostes, Juiz de Fora, v. 68, nº 395, p. 2632, 2013.

MENDONÇA, Maria Beatriz Odebrecht Carvalho et al. Qualidade Físico-química de Amostras de Leite Cru Comercializadas Informalmente no Norte do Paraná. LC / UNOPAR Cient., Ciênc. Biol. Saúde. 2009;11(4):47-50.

MIGUEL, Giulianna Zilocchi et al. Caracterização físico-química de leite obtido de diferentes tipos de comercialização em Pontes e Lacerda MT. Revista de Ciências Agroambientais, Alta Floresta, v.8, n.1, p.103- 111, 2010.

NERO, Luís Augusto et al. Leite cru de quatro regiões leiteiras brasileiras: perspectivas de atendimento dos requisitos microbiológicos estabelecidos pela Instrução Normativa 51. Ciência e Tecnologia de Alimentos. Campinas, SP, Brasil, v.25, p.191-195, 2005.

NEVES, Rodrigo Balduino et al. Avaliação sazonal e temporal da qualidade do leite cru goiano tendo como parâmetros a contagem celular somática e a contagem bacteriana total. Archives of Veterinary Science, v.24, n.1, p.10-23, 2019.

ORGANIZACIÓN DE LAS NACIONES UNIDAS PARA LA AGRICULTURA Y LA ALIMENTACIÓN. Producción de alimentos de origen animal: código de prácticas de higiene para la leche y los productos lácteos - CAC/RCP 57-2004. $2^{\text {a }}$ ed. Roma: FAO/OMS; 2009.

PAIVA, C.A.V et al. Evolução anual da qualidade do leite cru refrigerado, processado em uma indústria de Minas 
Gerais. Arquivo Brasileiro de medicina veterinária e zootecnia. v.64, n.2, p.471478, 2012.

PANTOJA JCF; REINEMANN DJ; RUEGG PL. Associations among milk quality indicators in raw bulk milk. J. Dairy Sci., v.92, n.10, p.4978-87, 2009.

PEDRICO, Angélica et al. Aspectos higiênico-sanitários na obtenção do leite no assentamento Alegre, município de Araguaína, TO. Ciência Animal Brasileira, v. 10, n. 2, p. 610-617, abr./jun. 2009.

PEREIRA, Juliano Gonçalves et al. Testes de Redutase para a Avaliação da Qualidade de Leite Cru Refrigerado. Revista Unopar Científica Ciências Biológicas e da Saúde, V. 14, n. 2, Pag. 77-80, 2012.

ROCHA, Karen Luiza; OLIVEIRA, Aline Pedrosa; CARVALHO, José Wilson Pires. Avaliação da Qualidade do leite "in natura”, pasteurizado e esterilizado (UHT), comercializado em Barra do Bugres-MT. ENCICLOPÉDIA BIOSFERA, Centro Científico Conhecer - Goiânia, v.13 n.23; p. 2016.

SANTOS, Marcos Veiga; FONSECA, Luís Fernando Laranja da. Estratégias para controle de mastite e melhoria da qualidade do leite. 1. Ed. Barueri; Manole, 2007.

SILVA, Polyanna Alves et al. Caracterização da qualidade do leite in natura de um laticínio de Campos Gerais, Minas Gerais. Ágora. Santa Cruz do Sul, v.19, n. 01, p. 34-47, jan./jun. 2017.

TAFFAREL, L.E.; COSTA, P.B.; OLIVEIRA, N.T.E.; BRAGA, G.C.; ZONIN. W.J. Contagem bacteriana total do leite em diferentes sistemas de ordenha e de resfriamento. Arq. Inst. Biol., São Paulo, v.80, n.1, p.7-11, jan./mar., 2013.
TONINI, Christyane Bisi. Avaliação da qualidade do leite e caracterização de laticínios do estado do Espírito Santo. Dissertação (Mestrado em Ciências e Tecnologia de Alimentos) - Universidade Federal do Espírito Santo, Alegre-2014.

VALSECHI, Octávio Antônio. Tecnologia de Produtos Agrícolas de Origem Animal: o leite e seus derivados. Universidade Federal de São Carlos, Araras - São Paulo: 2001.

ZOCCHE, F. et al. Qualidade Microbiológica e físico-química do leite Pasteurizado Produzido na Região Oeste do Paraná. 2002. 